\title{
Economic Thought: A Brief History
}

\author{
by Heinz D. Kurz \\ (Translation by Jeremiah Riemer of Geschichte des ökonomischen Denkens) \\ Columbia University Press, New York, 2016, xi + 208 pp.: 978-0-231-17258-5 \\ Reviewed by: Harry Bloch, Curtin University
}

Heinz Kurz has provided us with a delightful little book. More than a history of economic thought, it is a discourse on economic theory past and present written by a distinguished scholar of the history of economic thought. At a time when economic teaching has largely abandoned reflecting on the origins of modern orthodoxy and abstains from mentioning alternatives, here is an ideal antidote for the inquiring mind who desires a broad but brief overview of the development of economic theory.

In the short introduction, Kurz openly admits every history depends on the vision of the writer. He then declares his position on perhaps the most divisive issue among historians of economic thought, 'Is the market for economic ideas a perfectly functioning selection mechanism? Unfortunately, the answer is no.' (Kurz, 2016, p. 2) He follows up with a volume containing an open and dispassionate account of the contributions to economic theory from a wide array of individuals across a broad range of schools of thought.

Kurz also reminds us of the co-evolution of modern economies and the study of economics. He points to the phenomenal growth of economic activity and the associated rise in population since the agricultural and industrial revolutions in Europe starting from the early eighteenth century, suggesting the blossoming of the European study of political economy over the same period is not coincidental. This establishes a rationale for focusing coverage in the book on European intellectual traditions and their modern continuation, but basic references are nonetheless provided for the reader interested in Chinese or Islamic economic thought.

The substantive chapters of the book can be divided into four parts of three chapters each. The first three chapters deal with classical economics, its antecedents and its further development by Karl Marx. Following are three chapters on the development of neoclassical economics in continental Europe and Britain from the late nineteenth through the early twentieth century. There are then three chapters dealing with challenges to neoclassical competitive general equilibrium analysis, including a chapter on imperfect competition, one on Schumpeter and one on Keynes. The final three chapters are devoted to more recent developments, including the reaction to Keynes, modern general equilibrium analysis and a speedy tour through selected fields of inquiry from game theory through to financial market theory with stops in between for capital theory, growth theory and a smattering of other topics of recent interest. 
The book is noteworthy for the breadth of its coverage. The treatment of recent developments in economic thought is substantial by usual standards for histories of economic thought. Consistent with Kurz's commitment to pluralism, there is also substantial treatment of nonmainstream schools of thought, including, for example, commentary on the approaches of monopoly capital, American institutionalists, market socialists and the "third way", evolutionary economics, post-Keynesians and the Austrian school.

Kurz is careful to place the development of ideas in their historical context, as with the observation in the introduction about the parallel rise in economic activity and economic theorising in Western Europe. Further notable examples are relating the increase in theorising about imperfect competition to the rise in industrial concentration from the late nineteenth century and relating Keynes's work on the General Theory to the onset of the Great Depression. Theoretical developments in mercantilism, socialism and Marxism are also all placed in the context of contemporaneous historical conditions.

Space is saved in the book by consolidation. Many contributors to the development of economic thought are mentioned, but only a few have their individual views on specific issues elaborated. Instead, Kurz heavily relies on summaries of key features in common across many individuals. For example, in the chapter on classical economics the reader is provided with eight general features that characterise classical thinking, then, in the chapter on the rise of marginalism, eight general features of marginalist thinking are provided and a comparison made between these and the features of classical economics.

The comparisons between classical and marginalist thinking are illustrative of a great strength of the book, the author's ability weave together various elements of economic thought. Kurz notes marginalism shifts the focus of economic analysis from social classes to the needy isolated individual by adopting the subjectivist approach of methodological individualism. Also, production loses centre place as determining value, with consumption taking equal weight and substitution emphasised in both production and consumption. Marginalism further casts decision making in terms of constrained optimisation problems, which, with the use of ceteris paribus assumptions, leads to the development of partial equilibrium analysis compared to the long-run equilibrium focus of classical thinking. I find these comparisons illuminating, but others might view them as missing the point.

Another space saver in the book is that only limited biographical information is provided on even leading figures. There are a few anecdotes included to entertain the reader, such as the observation that Madame de Pompadour, Louis XV's mistress, assisted her personal physician, Françios Quesnay, with the publication of his Tableau Économique. Otherwise, little attempt is made to explain the views of economists in terms of their personalities or individual circumstances. It is the ideas and their relation to each other that are centre stage rather than the idiosyncrasies of their creators.

The flow of the book is smooth and easy in part because of the absence of footnotes or equivalent digressions in the text. Kurz offers observations and interpretations without diversion for demonstrating validity through extensive quotation of original sources. Where 
quotations are offered they generally are meant to capture the original author's style through the turn of phrase or the coining of terminology. Tellingly, there are no page numbers given for the quotations and sometimes only the author is identified without attribution to a particular publication.

One must cut corners to achieve the book's breadth of coverage in just over two hundred pages. Fortunately, the immense knowledge and sound judgement of the author results in a book that conveys the big picture and provides many valuable leads for further investigation. Even scholars in the history of economic thought should be able to find interest in the sometimes novel interpretations and connections. They should certainly keep the book in mind for recommendation to the novice with an inquiring mind or when recommending supplementary texts for standard introductory courses in economics.

\section{References}

Kurz, Heinz D. 2016. Economic Thought: A Brief History (translated by Jeremiah Riemer). New York, Columbia University Press.

Kurz, Heinz D. and Neri Salvadori 1995. Theory of Production. A Long-Period Analysis. Cambridge, Cambridge University Press. 